\title{
Editorship at REES
}

\section{Renewable Energy and Environmental Sustainability}

\author{
Ali Sayigh (Professor) (REES Editor-in-Chief) ${ }^{*}$
}

It gives me a great pleasure to introduce our new open access journal Renewable Energy and Environmental Sustainability (REES), teaming with the well-known major publisher - EDP Sciences, which publishes more than 70 journals and many books, owned by learned societies the as French Physical Society, French Chemical Society, etc. I continue to be passionately interested in the communication of all fields of renewable energy research and development. To this end following much discussion, I have agreed to become the Editor-in-Chief of this new journal.

During the last 26 years and since the establishment of the "World Renewable Energy Congress in the UK", renewable energy has become increasingly important as a vital source of clean and affordable energy. In this period, the immeasurable damage to the environment and health from the excessive use of fossil fuels as the major energy source has at last been recognized by most scientists and policy makers. Thus last December (2015), representatives of 190 countries met in Paris at the United Nations Climate Change Conference 2015 (COP21) where declared that:

- the earth temperature should not increase more than $1.5^{\circ} \mathrm{C}$;

- each country pledged to make zero $\mathrm{CO}_{2}$ in this century;

- the creation of an annual fund US\$1000 billion to help those effected by climate change;

- to check on progress every 5 years.

This was signed by 180 countries including USA, China and Japan.

The change in balance from the preponderance of fossil fuels to renewable energy is reflected in the levels of investment so far during the last 4 years renewable energy investment in excess of US\$320 billion while investment in oil and gas was below US $\$ 250$ billion.

Increasing numbers of scientists and engineers are actively involved in research, development and production of renewable energy systems and their industrial achievement has led to clean sources of energy at affordable cost.

\footnotetext{
* e-mail: asayigh@wrenuk.co.uk
}

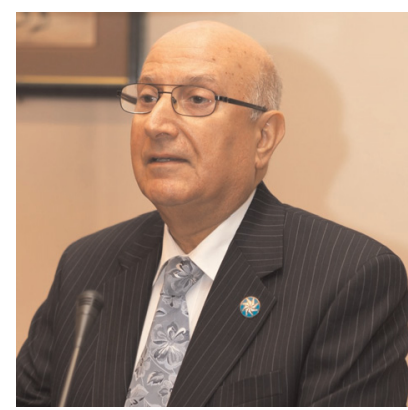

This had led to the increasing importance of renewable energy scientific publications and the necessity for speedy publication and access.

\section{Aims of REES}

The aims of REES are to invite original papers from scientists, researchers and industry professionals in "all fields of renewable energy, green building and sustainable development". It is increasingly understood that traditional research which has viewed pivotal areas of inquiry such as renewable energy, energy efficiency, sustainable development, green building, energy policy, and the energy-water nexus as separate academic or professional fields has become inadequate and outmoded. Intersectional and collaborative efforts across these inextricably intertwined areas are the new order of business to meet the new challenges facing sustainable technology research and implementation. This new journal addresses this emergent cross-functional reality, aiming to encourage original, innovative research and applications across all areas of renewable energy and sustainability. The journal supports publication of high quality research papers and technical notes as quickly and rigorously as possible through frequent issue releases and thorough peer-review. The ultimate goal of the journal is to encourage the reduction of energy consumption in the built environment, industry, agriculture, power systems, and transport by decreasing the utilization of fossil fuels, leading to the reduction of carbon emissions and greenhouse gases, and offsetting the impacts of climate change.

REES will accept manuscripts related to the following topic areas:

- Photovoltaic Technology;

- Solar Thermal Applications;

- Solar Desalination;

- Green Building Design;

- Low Energy/Sustainable Architecture;

- Energy Efficient Building Retrofitting;

- Energy Management;

- Biomass and Biogas Applications; 
- Waste to Energy;

- Wind Energy Technology;

- Hybrid and Combined Cycle Power Plants;

- Distributed Energy Generation;

- Hydrogen and Fuel Cell Technology;

- Ocean and Tidal Energy Technology;

- Geothermal Applications;

- Hydro Power;

- Meteorology and Climate Change;

- Renewable Energy Grid Integration;

- Energy Conservation;

- Energy Efficiency;

- Energy Policy;

- Sustainability Education Issues.

These topics will be managed by outstanding experienced Associate Editors from: Germany, China, Denmark, Greece, Ireland, Sweden, Canada, and UK.

REES is aimed towards researchers, academics and professionals working in the trans-disciplinary areas of renewable energy, green buildings, and sustainability, as well as energy industry and management, building technologists, architects, energy planners and policy makers, academic and institutional libraries, environmentalists and climate change scientists. Of particular importance are those working in cross-functional areas combining various topics within these areas.
REES will publish original research articles, short communications, invited reviews, technical and observational reports, strategic and educational articles, articles related to innovative architecture and energy conservation and buildings services, and concise projects reports.

All manuscripts are peer reviewed according to the quality standards of international scientific journals. It is therefore required that all manuscripts submitted for publication in REES contain new insight; present the results against a properly referenced background of existing work; present adequate evidence that supports the conclusions; written clearly concisely and comprehensively in English and include all necessary and appropriate figures and tables.

- Accepted papers are published in electronic form only.

- EDP Sciences maintain an electronic open access of all published papers.

- REES will be indexed in cross-reference and therefore will appear in all the international Digital Library reference systems.

The Associate Editors and the Editor-in-Chief believe that this journal will receive a wide readership and soon become a recognized source of innovative and exciting papers in the renewable energy and buildings sustainability disciplines. 